\title{
Fabrication of anatase titanium dioxide nanotubes by electroless deposition using polycarbonate for separate casting method
}

\author{
M. Boehme*, G. Fu, E. lonescu and W. Ensinger
}

Titanium dioxide nanotubes (TNTs) were prepared by electroless deposition using ion track etched polycarbonate templates. The ion tracks were prepared to the desired diameter of the TNTs outer diameter. Titanium dioxide nanotubes with a diameter of minimum $80 \mathrm{~nm}$ having a wall thickness of minimum $10 \mathrm{~nm}$ can be fabricated using this method. To achieve nanotubes with thin walls and small surface roughness the tubes were generated by a several steps procedure under aqueous conditions at nearly room temperature. The presented approach will process open end nanotubes with well defined outer diameter and wall thickness. Using this method TNT arrays up to $10^{9}$ tubes per $\mathrm{cm}^{2}$ having a tube length up to $30 \mu \mathrm{m}$ can be produced, single tubes are also possible. The structural properties of the grown TNTs were investigated by using various analytical techniques, i.e. scanning electron microscopy (SEM), energy dispersive X-ray fluoresence spectrometer (EDX), X-ray photoelectron spectroscopy (XPS), X-ray diffraction (XRD), Raman spectroscopy and Photoluminescence.

Keywords: Electroless deposition; Ion track template; Nanotubes; Titanium dioxide; Anatase

Citation: M. Boehme, G. Fu, E. Ionescu and W. Ensinger, "Fabrication of anatase titanium dioxide nanotubes by electroless deposition using polycarbonate for separate casting method", Nano-Micro Lett. 2, 22-26 (2010). doi:10. $\underline{\text { 5101/nml.v2i1.p26-30 }}$

Semiconductive nanostructures have reached strong significance in science and engineering. For many of these materials reliable syntheses are available now and a wide range of applications in all areas of nanoscience and nanotechnology have become possible. In case of semiconductive nanomaterials anatase titanium dioxide seems to be very interesting as a result of its pivotal role in photochemical solar cells with high conversion efficiency, caused of its large band gap from $3.2 \mathrm{eV}$ corresponding to $387 \mathrm{~nm}$. Due to its characteristics anatase titanium dioxide nanostructures could have novel applications in solar energy conversion, oxygen sensitivity, photocatalysis and humidity measurements [1,2].

For deposition of anatase titanium dioxide nanostructures there have been miscellaneous methods like electro spinning, sol-gel method or chemical vapor condensation developed and used [3-6]. To fabricate metal nanostructures the template deposition method, pioneered by C. R. Martin, is one of the important processes $[7,8]$. So far, various types of nanostructures obtained by electroless deposition have been successfully fabricated using chemical and physical methods [9-11]. However, synthesis of anatase titanium dioxide nanotubes by electroless deposition has not been reported yet.

In this announcement, we describe an effective synthesis of anatase titanium dioxide nanotubes (TNT) with a diameter of approx. $100 \mathrm{~nm}$ and a wall thickness of approx. $10 \mathrm{~nm}$. The anatase titanium dioxide nanotubes were grown by electroless deposition under aqueous conditions in ion track etched polycarbonate templates. Due to its surface limitation electroless deposition is a convenient and power saving manner to engender hollow nanostructures. The structural properties of the grown anatase titanium dioxide tubes were investigated by using various analytical techniques. The growth mechanism of the 
anatase titanium dioxide nanotubes was proposed on the basis of experimental results.

\section{Experimental Section}

\section{Sample preparation}

The template consists of polycarbonate foils with a thickness of 6 to $30 \mu \mathrm{m}$. Herein we used off the shelf polycarbonate membrane filters, exposed in a very controlled way to charged particles in a nuclear reactor, sold by Whatman/GETM and comparable companies. In order to remove an undesired surface treatment of polyvinylpyrrolidone (PVP) of the commercial membrane filters, we used an additional etching process.

Therefore the off the shelf polycarbonate foils were chemically etched at $50^{\circ} \mathrm{C}$ using a $6 \mathrm{~N} \mathrm{NaOH}$ solution containing $1 \%$ surfactant [12]. The resulting pore diameter is increasing linearly with etching time; the pores are of cylindrical shape.

In this report we created templates with a pore diameter of approx. $100 \mathrm{~nm}$.

\section{Sensitization and activation}

Prior to the electroless deposition process the surface of the polycarbonate template was treated with sensitization and activation solutions. In this way the template surface becomes catalytically activated and deposition on the surface is possible. Best results are obtained using the following procedure. The sensitization was performed by an aqueous $\mathrm{SnCl}_{2}$ solution containing $0.25 \mathrm{~mol} / \mathrm{L} \mathrm{SnCl}_{2}$ and $0.3 \mathrm{~mol} / \mathrm{L}$ hydrochloric acid for approx. $30 \mathrm{~min}$ at $45^{\circ} \mathrm{C}$. After rinsing the sensitized template with deionized water for one minute it was placed in the aqueous activation solution containing $0.2 \mathrm{~mol} / \mathrm{L} \mathrm{AgNO}_{3}$ and $0.02 \mathrm{~mol} / \mathrm{L} \mathrm{Co}\left(\mathrm{NO}_{3}\right)_{2}$ for a minimum of $10 \mathrm{~min}$, followed by rinsing in deionized water for one minute. To complete the activation process the template was placed for a minimum of 15 $\mathrm{min}$ in an aqueous solution containing $0.5 \mathrm{~mol} / \mathrm{L} \mathrm{Pd}\left(\mathrm{NO}_{3}\right)_{2}$, $0.02 \mathrm{~mol} / \mathrm{L} \mathrm{Ag}_{2}(\mathrm{SO})_{4}, 0.15 \mathrm{~mol} / \mathrm{L}$ hydrochloric acid and some drops of tetrafluoroboric acid at $65^{\circ} \mathrm{C}$. After rinsing with deionized water for $1 \mathrm{~min}$ the template was prepared for electroless deposition.

\section{Electroless deposition}

The last step is the electroless deposition of titanium dioxide. To obtain titanium dioxide nanostructures preferably titanium dioxide nanotubes, the sensitized and activated template was dipped into an aqueous solution containing $0.29 \mathrm{~mol} / \mathrm{L}$ $\mathrm{Ti}_{2}\left(\mathrm{SO}_{4}\right)_{3}$ and $0.8 \mathrm{~mol} / \mathrm{L}$ dimethylamine borane $\left(\mathrm{C}_{2} \mathrm{H}_{10} \mathrm{BN}\right)$. The used deionized water was oxygenated in advance to assure an oxygen concentration of around $13 \mathrm{mg} / \mathrm{L}$. The temperature of the deposition bath was $2^{\circ} \mathrm{C}$ to get best results. At the end of the deposition time the template with the inner grown TNTs was rinsed with deionized water for several minutes. Afterwards the TNTs were annealed at $310^{\circ} \mathrm{C}$ under normal air pressure for $1 \mathrm{~h}$. The time of deposition can be varied regarding the desired wall thickness. In this work the deposition time was 12 min with the result of approx $10 \mathrm{~nm}$ wall thickness.

\section{Characterization}

After the plating process scanning electron microscopy (SEM) was used for morphology and size distribution investigations of the nanostructures. Therefore the polycarbonate covering the TNTs was removed easily using dichloromethane. Energy dispersive X-ray (EDX) analysis was performed to determine the element composition. To get structural information about the phase composition of the TNTs we used $\mathrm{X}$-Ray Diffraction (XRD) with $\mathrm{Cu} \mathrm{K \alpha}(\lambda=1.5408 \AA)$ radiation. The chemical composition of the TNTs was analyzed by X-ray photoelectron spectroscopy (XPS) using monochromatic Al K $\alpha$ radiation $(\mathrm{h} v=1486.6 \mathrm{eV})$. The TNTs fluorescence emission at room temperature was studied using a fluorescence spectrophotometer (Cary Eclipse, Varian) at an excitation wavelength of $310 \mathrm{~nm}$. Further on for optical characterization Raman spectroscopy was used at $488 \mathrm{~nm}$ laser excitation. The laser power on the sample surface is about $8 \mathrm{~mW}$ with a spot size of $1.5 \mu \mathrm{m}$.

\section{Results and Discussion}

\section{Chemical reaction mechanism}

At first we will discuss the reaction mechanism of the three steps prior to the $\mathrm{TiO}_{2}$ deposition step. During the sensitization process the tin chloride is hydrolyzed (reaction 1) to modify the surface of the etched polycarbonate template with $\mathrm{Sn}^{2+}$-ions by electrostatic attraction. It is observed that after putting the polyester fabrics in an acidic $\mathrm{SnCl}_{2}$ bath, $\mathrm{Sn}^{2+}$-ions are adsorbed onto the particle surface, forming a uniform layer [13].

Subsequently with the activation step a redox reaction is carried out on the surface of the modified template; by the addition of $\mathrm{Ag}^{+}$-ions, on which $\mathrm{Sn}^{2+}$-ions are oxidized to $\mathrm{Sn}^{4+}$-ions. At the same time $\mathrm{Ag}^{+}$-ions are reduced into metallic $\mathrm{Ag}$ that forms $\mathrm{Ag}^{0}$ cluster on the template surface (reaction 2). Using an aqueous $\mathrm{PdCl}_{2}$ solution the $\mathrm{Ag}^{0}$ clusters are oxidized to $\mathrm{Ag}^{+}$and will go into solution, within the same time the $\mathrm{Pd}^{2+}$-ions are reduced to $\mathrm{Pd}^{0}$ to form palladium cluster on the template surface (reaction 3). Following these steps using the parameter named in the experimental section of this report, we are able to produce more than 2000 nuclei per $\mu \mathrm{m}^{2}$, which is one of the keys to achieve the reported TNTs.

Senzitation:

$\mathrm{SnCl}_{2} \rightarrow \mathrm{Sn}^{2+}+2 \mathrm{Cl}^{-}$

Activation:

$\mathrm{Ag}^{+}+\mathrm{Sn}^{2+} \rightarrow \mathrm{Ag}^{0}+\mathrm{Sn}^{4+}$

Palladium cluster formation:

$\mathrm{PdCl}_{2}+2 \mathrm{Ag}^{0} \rightarrow \mathrm{Pd}^{0}+2 \mathrm{Ag}^{+}+2 \mathrm{Cl}^{-}$

To discuss the growth mechanism of the TNTs induced by electroless deposition method the general chemical deposition mechanism of $\mathrm{TiO}_{2}$ in the solution can be supposed as follows:

$$
\begin{aligned}
& \mathrm{Ti}_{2}\left(\mathrm{SO}_{4}\right)_{3} \rightarrow 2 \mathrm{Ti}^{3+}+3 \mathrm{SO}_{4}{ }^{2-} \\
& \left(\mathrm{CH}_{3}\right)_{2} \mathrm{NHBH}_{3}+2 \mathrm{H}_{2} \mathrm{O} \rightarrow \mathrm{BO}^{2-}+\left(\mathrm{CH}_{3}\right)_{2} \mathrm{NH}+7 \mathrm{H}^{+}+6 \mathrm{e}^{-} \\
& \mathrm{SO}_{4}{ }^{2-}+\mathrm{H}_{2} \mathrm{O}+2 \mathrm{e}^{-} \rightarrow \mathrm{SO}_{3}{ }^{2-}+2 \mathrm{OH}^{-}
\end{aligned}
$$




$$
\begin{aligned}
& \mathrm{Ti}^{3+}+3 \mathrm{OH}^{-}+2 \mathrm{H}_{2} \mathrm{O} \rightarrow \mathrm{Ti}(\mathrm{OH})_{5}{ }^{-}+2 \mathrm{H}^{+} \\
& \mathrm{Ti}(\mathrm{OH})_{5}{ }^{-}+\mathrm{H}^{+} \rightarrow \mathrm{TiO}_{2}+3 \mathrm{H}_{2} \mathrm{O}
\end{aligned}
$$

Firstly, the $\mathrm{Ti}_{2}\left(\mathrm{SO}_{4}\right)_{3}$ is hydrolyzed, as shown in reaction (4). Simultaneously dimethylaminoborane (DMAB) is hydrolyzed and free electrons are released (reaction 5). Therefore the $\mathrm{SO}_{4}{ }^{2-}$-ions can acquire electrons to be reduced to $\mathrm{SO}_{3}{ }^{2-}$-ions, followed by an increase of the $\mathrm{OH}^{-}$-concentration (reaction 6). The $\mathrm{OH}^{-}$ions will combine with $\mathrm{Ti}^{3+}$ to build intermediate products such as $\mathrm{Ti}(\mathrm{OH})_{5}{ }^{-}$in solution (reaction 7). Because of ionic diffusion, deregulation movement between molecules and ions in the solution and heat confection inside the etched ion tracks, the nanotubes are induced by the dehydration reaction between $\mathrm{OH}^{-}$- and $\mathrm{H}^{+}$-ions, explained in reaction (8). It is well understood that the mode of nucleation, which is a heterogeneous nucleation on surfaces of substrates or homogeneous nucleation in solution, is determined by the supersaturation solution [14]. When the solution is supersaturated, nucleation begins; $\mathrm{TiO}_{2}$ nanocrystallits form on the template surface due to the palladium clusters placed on the surface, using the steps before deposition. As the reaction continues, more $\mathrm{TiO}_{2}$ crystallites appear in the solution and the nanotubes are formed.

\section{Deposition characteristics}

To get further information about the repeatability of the described method four different samples with TNTs with an expecting wall thickness of 10, 20,30 and $40 \mathrm{~nm}$ were prepared. Each sample was prepared to get a bulk material sample for SEM investigation, similar to the sample shown in Fig. 1 (b) and Fig. 1 (c). The samples were manually scanned for tubes having a position to measure their wall thickness. Around 150 200 tubes of each sample were surveyed to get best results for a Gaussian distribution wall thickness plot shown in Fig. 2 (b-d). The maximum of the Gaussian distribution (xc) of each expected wall thickness is equal to the effective produced wall thickness of the particular sample and was plotted into the diagram shown in Fig. 2 (a). The error bars used in Fig. 2 (a) are the results of the
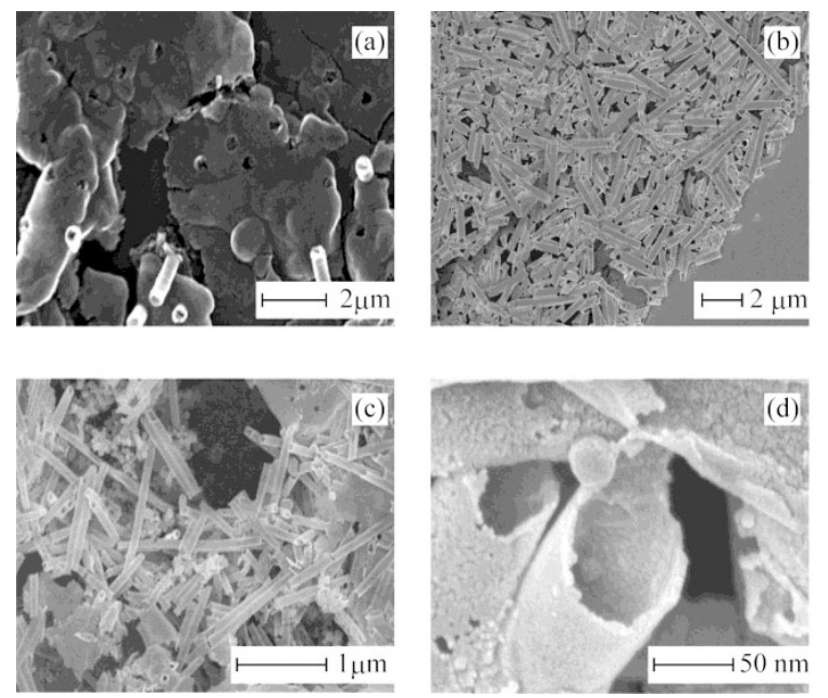

FIG. 1. (a) SEM image of the removed $\mathrm{TiO}_{2}$ layer from the template surface. (b) - (d) SEM image of bulk TNTs unhinged from polycarbonate template.
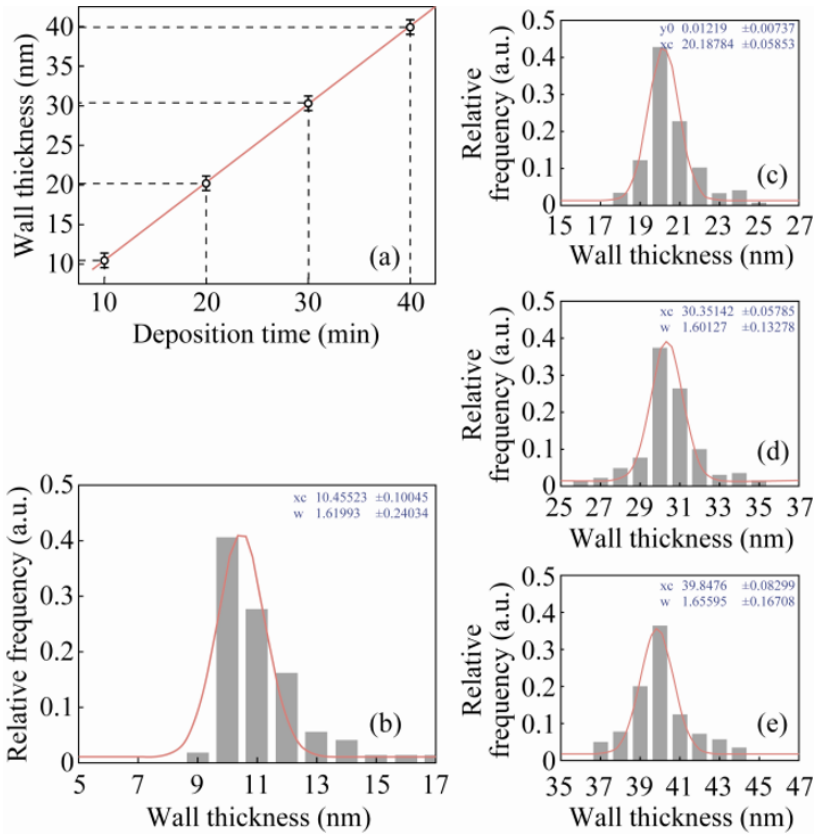

FIG. 2. (a) Deposition time vs. wall thickness plot. (b) Gaussian distribution of $10 \mathrm{~nm}$ wall thickness TNTs. (c-e) Gaussian distribution of 20, 30 and $40 \mathrm{~nm}$ wall thickness TNTs.

2 sigma values (w) from the Gaussian distribution of the respective sample.

As a result, Fig. 2 shows, using the deposition method, as described previously in this report, it is possible to produce TNTs with defined wall thickness of high accuracy. This means in numbers, if the desired wall thickness is $10 \mathrm{~nm}$, the maximum of the Gaussian distribution for the effective produced wall thickness is $10.46 \mathrm{~nm}$ having an irregularity of $\pm 0.8 \mathrm{~nm}$.

\section{Structural investigation}

Using polycarbonate templates for electroless deposition not only the deposition of the inner walls but also deposition of the template surface occurs. To use the template as feedstock for titanium dioxide nanotube arrays a minimum of one side of the coated surface has to be removed. To achieve bulk titanium dioxide nanotubes both sides of the coated template have to be removed before dissolving the template. We found the best way to remove the coated surface without damaging the fabricated tubes, is to use adhesive tape. Figure 1 (a) shows the surface of the adhesive tape-previously the adhesive side-with the removed template surface deposit sticking on the adhesive.

As shown in Fig. 1 (a) the removed titanium dioxide layer from the template surface mostly contains round nicks as a result of breaking up the nanotube/surface assembly leaving the nanotubes back in the template. In this work, both sides have been removed before dissolution of the polycarbonate for further investigation.

SEM images in Fig. 1 (b-c) shows the titanium dioxide nanotubes unhinged from the polycarbonate template. The outer diameter of the tube shown in Fig. 1 (d) is about $100 \mathrm{~nm}$, which is in relation to the etched ion track pore size of the polycarbonate. Using high resolution SEM the surface of the titanium dioxide nanotubes is observed to be even and clogged with high magnification. Merely a small surface asperity is 
ascribed to the gold sputtering layer, essential to get SEM pictures due to the poor electrical conductivity of undoped $\mathrm{TiO}_{2}$.

As expected, the nanotubes have open ends, indicating that the deposition of titanium dioxide solely occurred on the etched ion track walls. The tubes' wall thickness is linear related to the electroless deposition conditions. As described before, the deposition time in this work was 12 minutes and seems to be the minimum time value to achieve stable and non fragmental TNTs. With shorter deposition times, we just got cluster formation on the tube wall surface without obtaining tubular structures.

Using the introduced deposition method it is possible to assign an exact desired wall thickness simply by adjusting the deposition time. With short deposition time tubes were achieved, while overstay deposition time increased the wall thickness and nanowires with a small open core along their longitudinal axis were obtained finally. The reproducibility of the deposition method using polycarbonate templates was investigated by a survey over a significant number of examinable tubes by different deposition times, as previously shown in Fig. (2).

In Fig. 3 (d) the X-Ray diffraction pattern of the fabricated TNTs is shown. The XRD-pattern shows that the TNTs consist of the two $\mathrm{TiO}_{2}$ modifications rutile and anatase. The reflex distribution of each modification agrees very well with literature data [15], both in terms of the 2 theta peak positions and the relative reflex intensities. Further on, the structural compounding of the TNTs could be calculated based on the XRD-Data; as result the TNTs consist of approx. $82 \%$ anatase and approx. $18 \%$ rutile. We assume that the rutile phase accrues from the annealing process, which was used to get high ordered structures. Due to the photocatalytic behaviour of anatase, the produced TNTs would be preferably used for similar or photovoltaic applications. Taking into account that the photocatalytic activity is enhanced using mixed phase $\mathrm{TiO}_{2}$ [16], the achieved TNTs will have better capabilities than pure anatase nanostructures. The enhanced photocatalytic activity could be explained as the

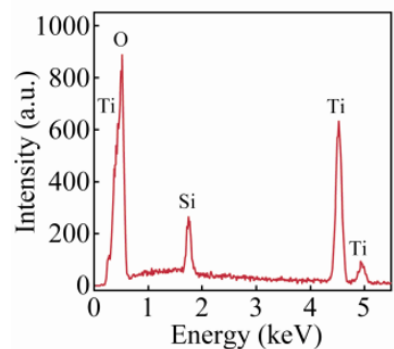

(a)

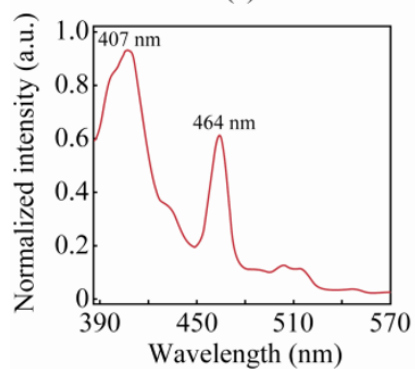

(c)

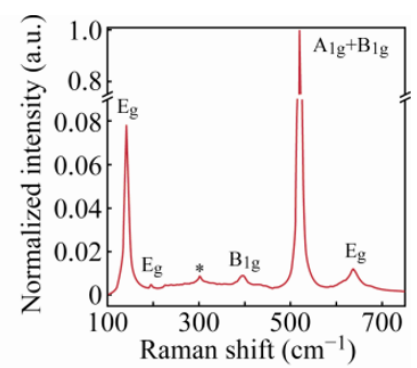

(b)

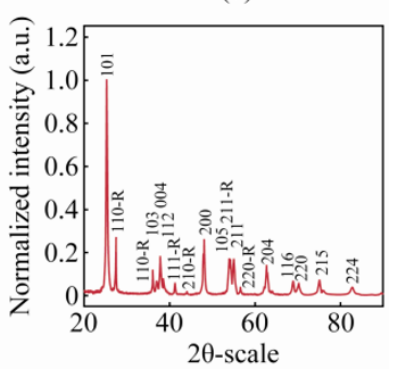

(d)
FIG. 3. (a) EDX spectrum of titanium dioxide nanotubes dissected silicon waver. (b) Normalized Raman Scattering spectrum of the TNTs. (c) Normalized PL spectra of the TNTs excited at $310 \mathrm{~nm}$. (d) XRD-pattern of the TNTs, rutile reflexes marked with hkl-R, anatase only hkl. transition points between rutile and anatase allow rapid electron transfer from rutile to anatase [16]. It will be very interesting and useful to control the percentage of anatase and rutile phase within the TNTs, so we currently work on further investigation in this direction.

The EDX spectra of the unhinged TNTs showed in Fig. 3 (a) feature peaks corresponding to elements $\mathrm{Si}$, Ti and $\mathrm{O}$ peaks, which depict the characteristic composition of the desired TNTs and confirm the presence of titanium dioxide. The Si peak arises from the silicon wafer the tubes were stored on for handling purposes.

The Raman spectrum for the grown TNTs is shown in Fig. 3 (b). The frequency and symmetry of the fundamental Raman active phonon modes for the fabricated TNTs are similar to the six allowed bands $\left(1 \mathrm{~A}_{1 \mathrm{~g}}+2 \mathrm{~B}_{1 \mathrm{~g}}+3 \mathrm{E}_{\mathrm{g}}\right)$ investigated by Ohsaka et al [17].

As shown in Fig. 3 (b) the Raman spectrum exhibits five peaks located at $E_{\mathrm{g}} 143 \mathrm{~cm}^{-1}, E_{\mathrm{g}} 197 \mathrm{~cm}^{-1}, B_{1 \mathrm{~g}} 397 \mathrm{~cm}^{-1}, A_{1 \mathrm{~g}}+B_{1 \mathrm{~g}}$ $520 \mathrm{~cm}^{-1}$ and $E_{\mathrm{g}} 638 \mathrm{~cm}^{-1}$, as well as one weak broad feature at $302 \mathrm{~cm}^{-1}$, marked as *. The good accordance of the measured Raman Spectrum with the literature confirms that the fabricated nanotubes consist of anatase titanium dioxide [17].

Figure 1 (c) presents the fluorescence behaviour of the fabricated TNTs. The excitation wavelength used in the study was $310 \mathrm{~nm}$. The fluorescence spectrum shows two strong UV emission peaks at $407 \mathrm{~nm}$ and $464 \mathrm{~nm}$ as reported for anatase $\mathrm{TiO}_{2}$ nanostructures and confirms one more time the presence of
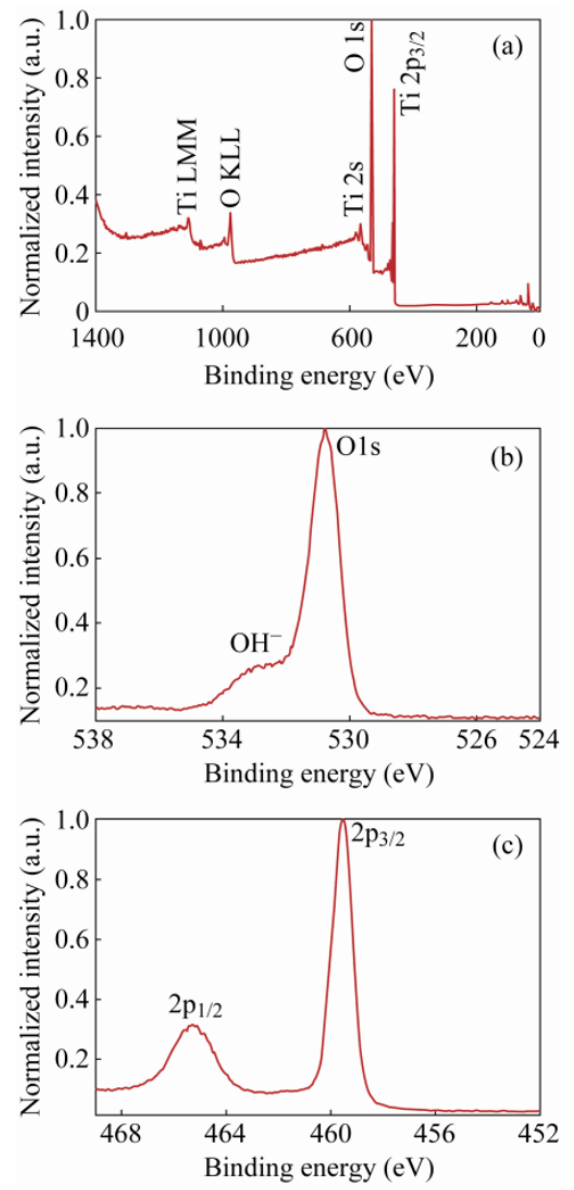

FIG. 4. XPS spectra of the synthesized TNTs (a) full range survey spectrum, (b) O 1s spectrum, (c) Ti $2 \mathrm{p}_{3 / 2}$ spectrum. 
anatase titanium dioxide [18].

The composition of the fabricated TNTs was further determined using XPS. The resulting full range survey spectrum is shown in Fig. 4 (a). The two strongest peaks of the survey spectrum were investigated closely in additional spectra shown in Fig. 4 (b-c). They are located at binding energies of $530.8 \mathrm{eV}$ and $459.5 \mathrm{eV}$ respectively to the $\mathrm{O}(1 \mathrm{~s})$ and $\mathrm{Ti}\left(2 \mathrm{p}_{3 / 2}\right)$ binding energies for $\mathrm{TiO}_{2}$. Comparing the binding energies shown in Fig. 4 (a-c) with literature values, the composition of the fabricated nanotubes was consistent with stochiometric $\mathrm{TiO}_{2}$ $[19,20]$. With further detailed examinations, these results are in good accordance with anatase $\mathrm{TiO}_{2}$ single crystals [21,22].

\section{Conclusion}

Bilateral open cylindrical largely anatase titanium dioxide nanotubes with controllable diameter and wall thickness were fabricated using electroless deposition based on aqueous solutions. This method can be extended to other materials. The developed TNTs have lots of potential applications in fields like sensing, photocatalysis or regenerative energy. Using polycarbonate as template it is possible to produce TNT arrays within the size of the polycarbonate having a tube density from a single up to $10^{9}$ tubes $/ \mathrm{cm}^{2}$. These arrays can be directly used for sensor and photovoltaic applications.

Received 2 February 2010; accepted 4 March 2010; published online 20 March 2010.

\section{References}

1. A. Cox, Photochemistry 22, 505 (1992). doi:10.1039/978 $\underline{1847554727-00505}$

2. R. J. Gonzalez and R. Zallen, NATO ASI Proceedings, ed. By M.F. Thorpe (1997).

3. D. Li and Y. Xia, Nano Lett. 4, 933 (2004). doi:10. $\underline{1021 / \mathrm{n} 1049590 \mathrm{f}}$

4. A. Sadeghzadeh, M. S. Ghamsari and J. Mater. Sci. 43, 5924 (2008). doi:10.1007/s10853-008-2872-y
5. T. Maiyalagan, B. Viswanathan and U. V. Varadaraju, Bull. Mater. Sci. 29, 7, 705 (2006).

6. J. Wu, G. Bai, J. A. Eastman, G. Zhou, V. K. Vasudevan and Symposium Z from the MRS Spring Meeting. (2005).

7. C. R. Martin, Science 23, 266, 5193 (1994).

8. J. D. Klein, R. D. Herrick, D. Palmer, M. J. Sailor, C. J. Brumlik and C. R. Martin, Chem. Mater. 5, 902 (1993). doi:10.1021/cm00031a002

9. L. A. Jr. Porter, H. C. Choi, A. E. Ribbe and J. M. Buriak, Nano Lett. 2, 10 (2002).

10. K. Valenzuela, S. Raghavan, P. A. Deymier and J. J. Hoying, Nano Sci. Nanotech. 8, 7 (2008).

11. Z. Shi, et al, Nanotechnology 17 (2006).

12. N. Chtanko, T. M. E. Molares, T. Cornelius, D. Dobrev and R. J. Neumann, Phys. Chem. B 108, 28 (2004).

13. S. Shukla, S. Seal, J. Akesson, R. Oder, R. Carter and Z. Rahman, Appl. Surf. Sci. 80, 35 (2001). doi:10.1016/S0 169-4332(01)00341-5

14. Mullin J W 1997 Crystallization (Oxford: ButterworthHeinemann).

15. JCPDS (1998) International Centre for Diffraction Data.

16. D. C. Hurum, A. G. Agrios, K. A. Gray, T. Rajh and M. C. Thurnauer, J. Phys. Chem. B 107, 4545 (2003). doi:10. 1021/jp0273934

17. T. Ohsaka, F. Izumi and Y. Fujiki, J. Raman Spectrosc. 7, 321-323 (1978). doi:10.1002/jrs.1250070606

18. D. Fang, K. Huang, S. Liu and J. J. Huang, Braz. Chem. Soc. 19, 6, 1059 (2008).

19. M. Murata, K. Wakino and S. J. Ikeda, Electron. Spectrosc. 6, $459 \quad$ (1975). $\quad \underline{\text { doi:10.1016/0368- }}$ 2048(75)80032-6

20. D. Gonbeau, C. Guimon, G. Pfister-Guillouzo, A. Levasseur, G. Meunier and R. Dormoy, Surf. Sci. 254, 81 (1991). doi:10.1016/0039-6028(91)90640-E

21. G. Silversmit, G. D. Doncker and R. D. Gryse, Surf. Sci. Spectrosc. 9, 21 (2002). doi:10.1116/11.20020701

22. G. Y. Hua, G. Yang, C. H. Sun, S. Z. Qiao, J. Zou, G. Liu, S. C. Smith, H. M. Cheng and G. Q. Lu, Nature 453, 638 (2008). doi:10.1038/nature06964 